\title{
Health Care Delivery Crisis In Corporate America
}

John J. Lucas, Purdue University Calumet

\begin{abstract}
This paper examines the health care delivery crisis that has emerged in corporate America. Health care costs now account for 17\% of the total GDP with the United States spending two trillion in health care costs (Herzlinger, 2007). The paper also discusses the major strategies that business leaders have implemented to reduce health care delivery costs while maintaining quality care for their employees. The effectiveness of these strategies to contain health care costs will also be addressed.
\end{abstract}

\section{BACKGROUND}

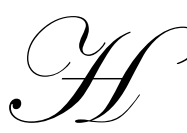

ealth insurance has been viewed by business leaders as an important component of benefit packages designed to attract and retain employees. The primary goal of health insurance was to afford financial protection for employees against medical expenses resulting from a major illness or accident. Over the past decade, corporate America has continued to experience soaring health care costs and these costs "continue to be their fastest growing expense." According to a survey conducted by the Employee Benefit Research Institute (EBRI), employers spent $\$ 514$ billion on health insurance or nine percent of their total spending on wages and benefits in 2005, as compared to $\$ 331$ billion or seven percent in 2000 (Consumer Reports, 2007). Additionally, the employer premium for family coverage was $\$ 11,480$ in 2006 which represented an eighty one percent increase since 2000 (Terchune, 2007).

In a recent survey conducted by Aon Consulting, a human capital consulting company, the cost of health care has been projected to increase by as much as 11.2 percent in the next twelve months (Gurchiek, 2007). This survey, representing seventy health insurers with more than 100 million insured individuals, also indicated the projected health care increases by health plan categories, including Health Maintenance Organizations (HMOs), Point of Service (POS) plans, Planned Provider Organizations (PPO) and Consumer-Driven Health Plans (CDHPs). HMOs rates were projected to increase by 10.9 percent, while POS plans were expected to rise by 10.8 percent. Additionally, PPO rates were projected to increase by 11.2 percent, with the projection of CDHPs rates to rise by 10.7 percent (Gurchiek, 2007). Therefore, the challenge for corporate America is to provide quality care for its employees while maintaining health care delivery costs. An important question remains whether employers can devise and implement corporate strategies in an effort to contain their health care delivery costs.

Corporate Strategies to Reduce Health Care Delivery Costs: With escalating health care delivery costs, business leaders have been particularly interested in creating and implementing strategies to reduce health care delivery costs and maximize profits, in order to compete in the global economy. One such strategy has been the implementation of Health Savings Accounts (HSAs) in the workplace. HSAs were created under Section 223 of the Medicare Prescription Drug, Improvement and Modernization Act of 2003. According to the Kaiser Family Foundation, 2.7 million U.S. workers were enrolled in these plans as compared to 2.4 million in 2005 (Fuhrmans, 2007).

HSAs have been described as a consumer-driven health care plans that allow employees to set aside pretax pay, combined with employer contributions, to pay for health care expenditures incurred by the employee. In other words, HSAs were a type of personal savings account, with a high deductible, that was used by an employee to pay for medical expenses. A high annual deductible was established by law of at least $\$ 1,050$ for an individual or $\$ 2,100$ for a family in order to qualify for this consumer-driven health care plan (Rubenstein, 2006). Additionally, 
the maximum HSAs contribution was $\$ 2,850$ for an individual or $\$ 5,650$ for a family. Furthermore, employees, aged 55 or older, may contribute an additional eight hundred dollars each year (DeBaise, 2007).

Major Fortune 500 companies, such as Walmart, Dalmer-Chrysler, General Motors, and Microsoft, have implemented HSAs in their workplace. Employers view these consumer-driven health plans as a strategy to save on escalating health care delivery costs by placing employees more directly in charge of their medical spending and becoming accountable for their own medical care (Kidd Stewart, 2006). Research data indicated that HSAs were accomplishing their goal and that employees enrolled in these plans tend to spend less on health care than others (Fuhrman's, 2007).

However, a controversy surrounding HSAs had emerged as critics argued that these plans were designed only for rich and healthy individuals, as they gain tax advantaged savings while having the ability to afford higher out-of-pocket medical expenses (Kidd Stewart, 2006). Additionally, there has been a growing trend in corporate America for HSAs to be increasingly used as another retirement savings vehicle, rather than to pay for current medical expenses. The appealing characteristic of HSAs was that there were no taxes paid on the investment growth or withdrawal of monies from the account, as long as it was used for medical expenses (DeBaise, 2007). Under a 401(k) plan, a very popular retirement savings plan, the monies withdrawn from the savings account were taxed. Therefore, the future use of HSAs as a viable strategy to reduce health delivery costs is uncertain.

Still another strategy to reduce health delivery costs has been the implementation of the so-called 'minimedical" plans or "limited benefit" plans offered by employers. The mini-medical plans or limited benefit plans have become one of the fastest growing trends sweeping corporate America. It has been estimated that nearly one million people have mini-plans and health plan insurers state that business has been growing by twenty percent a year (Fuhrmans, 2006). Major corporations, such as IBM, General Electric, Sears Holdings, and Avon Products, have offered these inexpensive health plans to their employees.

The intent of these plans has been to offer a very inexpensive health care plan, with a low weekly premium, to the employee in order to provide for only basic health services, such as doctor visits, prescription drugs, and laboratory expenses. However, these plans often cap annual payouts at $\$ 10,000$ or less and provide minimum coverage for hospital and emergency care (Fuhrmans, 2007). For example, OptiMed Health Plan is a mini-medical plan with a weekly premium of $\$ 13.02$ for single coverage and $\$ 35.31$ for family coverage. This plan provides a sixty dollar reimbursement per doctor visit and a ten dollar co-payment for generic drugs. The hospital benefit is limited to $\$ 500$ per day (www.optimedhealthplans.com) Another example is Starbridge Choices which has a $\$ 8.85$ weekly premium for single coverage and $\$ 31.75$ for family coverage. There is a $\$ 20.00$ co-payment for office visits, and the plan also reimburses at eighty percent, after a $\$ 50.00$ deductible, up to $\$ 1,000$ for other medical services. The plan provides a discount on brand and generic prices for prescription drugs and hospital benefits is paid at \$ 100 a day for a maximum of one hundred day (www.starhrg.com).

Evaluating both the OptiMed and Starbridge Choices mini-plans, the inexpensive weekly premiums have clearly been the attractive feature for both of these health plans. Some critics of these so-called mini-plans argue that employees simply enroll in these plans because of the inexpensive premiums and have not been fully aware of the plans' limitations (Fuhrmans, 2006). Proponents of these plans insist that the min-health plans offer preventive care for employees and also some type of health plan, when the alternative is no plan at all (Fuhrmans, 2006). Miniplans have grown enormously in popularity in the last few years because of their affordable health premiums for employees. Only time will tell if these mini-plans become a realistic and viable solution for corporate America to resolve the health care delivery crisis.

Health Promotion or Wellness Programs have been yet another approach utilized by business leaders to reduce their health care costs. These programs promote the physical and mental well-being of employees through a healthier lifestyle, in order to eliminate possible causes of future medical problems (Beam and McFadden, 2005). In other words, these health promotion or wellness programs have been designed to engage and encourage employees to modify their lifestyles and live healthier and more productive lives. 
Some typical corporate health promotion or wellness programs include: blood pressure and cholesterol screening, quit-smoking programs, health-risk assessments, subsidized weight-loss programs, annual physical exams, on-site medical clinics, health-club reimbursement programs, and a nurse care line. In the $12^{\text {th }}$ annual Watson Wyatt/National Business Group on Health Survey, companies had implemented a nurse line (78\%), health risk appraisal (72\%), programs to reduce obesity among employees (42\%), and had opened on-site medical clinics (23\%) (McQueen, 2007). This survey indicated that employers were very willing to implement these programs at the workplace in an attempt to encourage employees to live healthy and productive lifestyles in order to decrease the employee's risk of disease and chronic health problems. In essence, the primary goals of these health intervention programs were to encourage employees to modify their behavior in ways that would lead to healthier and more productive lives and also to reduce escalating health care costs.

Many organizations, such as Johnson and Johnson, Molson Coors Brewing Company, Dell Inc., Discovery Communication, Harrah's Entertainment, and Commonwealth Edison, have implemented such wellness programs to encourage their employees to live a healthier lifestyle. Wellness Solutions, a Health Promotion company based in San Diego, assists organizations and its employees by providing various health promotions and fitness management programs. Ronda Ryan, proprietor of Wellness Solutions, states that the goal of her company is to meet the fitness and wellness needs of organizations by working with them in order to decrease various lifestyles and disease risk factors of its employees. One successful client that Ryan identifies is the Anaheim Police Department. With their health and fitness program, 52 percent of the participants had decreased their cholesterol levels, 43 percent decreased their body fat percentages, and 72 percent had improved their cardiovascular fitness. Additionally, officers who fully participated in the Wellness Program reported 36 percent fewer injuries, 33 percent fewer strain/sprain injuries and 43 percent fewer back or knee strain injuries. Another client is Hewlett-Packard. Wellness Solutions completed 2,417 office ergonomic assessments for Hewlett Packard. Of the risks identified during the assessments, 77 percent have been reduced as a result of the comprehensive ergonomic and health education offered by Wellness Solutions.

Across the nation, other leading-edge companies are also experiencing success in the health promotion and interventions at the workplace. Commonwealth Edison implemented one of the earliest Health Awareness programs as the company experienced escalating health care expenditures. Jere Weliver, retired Director of Personnel at Commonwealth Edison, states that the need was clear to implement a Health Education Program at Commonwealth Edison, because medical claims indicated that employees were simply not conscious or concerned about how they used their medical benefits. Weliver identifies the Health Awareness committees established at each company location as an integral component of the company's Wellness Program. These committees were composed both of management and bargaining unit employees and were responsible for coordinating and implementing health education programs as well as conducting sessions aimed at how to better use health care benefits. Some of the health education programs developed at each company location included: blood and cholesterol screening, healthrisk appraisals, Health Fairs, and the support of "Great American Smokeout." Weliver also believes that another critical element to their Wellness Program that achieved great success was the establishment of the CARELINE. This was a phone center staffed with health care professionals, so that employees, retirees, and spouses could call and ask about their health concerns in a confidential environment.

Molson Coors Brewing provides employees a \$200 discount towards their annual health-care premiums, if they complete a health-risk appraisal and follow any medical advice given to them (McQueen, 2007). At Dell Inc., employees are allocated $\$ 75$ towards their annual health-care premium if they complete a health-risk assessment. Employees are also eligible for an additional $\$ 225$ if they complete a wellness program for managing health risks (McQueen, 2007). Discovery Communications has implemented a workplace clinic and estimates that it has saved $\$ 1$ million a year since the start of the clinic (McQueen, 2007).

It is apparent that many organizations have fully embraced health awareness or wellness programs as an opportunity to encourage employees to modify their lifestyles in a way that will lead to healthier and more productive lives. Some research studies show promising results that the implementation of health promotion or wellness programs at the workplace does result in lower levels of health care costs and absenteeism. Further research studies will be needed to provide conclusive evidence of the long-term effect of using health awareness or 
wellness programs at the worksite in an effort to reduce health risks and the cost of health care delivery.

\section{CONCLUSION}

This paper examined the health care delivery crisis that exists in corporate America, as business leaders continue to experience escalating medical care costs. This year, the cost of health care is projected to increase as much as 11.2 percent for large employers. The rising cost of medical care in the United States may be attributable to an aging population, increasing medical technology and hospital costs, increasing price and utilization of prescription drugs, poor lifestyle choices, and medical malpractice costs (Gurchiek, 2007).

Corporate America has responded with a variety of strategies to address the health care delivery crisis. One strategy has been the implementation of HSAs in the workplace. These consumer-driven health plans place employees more directly in charge of their own medical spending and health care (Kidd Stewart, 2006). However, according to a recent survey conducted by the Kaiser Family Foundation, only 19\% of the employees were willing to select HSAs when given a choice by their employers (Fuhrmans, 2007). The high-deductible requirement of HSAs may be a major factor for this relatively low selection choice by the employee.

Still another strategy to reduce health care delivery costs has been the offering of "mini-medical" plans or "limited benefit" plans. These health plans have gained enormous popularity in corporate America as a way to provide a very inexpensive health care plan for the employee. However, these plans only afford minimum coverage for health services and could become problematic for the employee with a major or chronic illness.

Many Fortune 500 companies have also taken the initiative in offering health promotion or wellness programs at the worksite in an effort to reduce their health care expenditures. These programs have been designed to engage employees and encourage them to modify their behavior to lead to healthier and more productive lives. Initial research studies indicate very promising results as these health interventions at the worksite do, in fact, reduce health care costs and absenteeism.

There is no single approach or strategy to resolve this complex and difficult health care delivery issue in corporate America. In recent years, major organizations have attempted to offset soaring health care costs by increasing employee premiums, deductibles, and co-payments. These additional requirements for health care coverage have placed an enormous financial burden on the employee. As a result, many employees have simply dropped the employer's health plan. From 1996 to 2004, the number of private-sector employees who enrolled in health care benefits offered to them dropped from $87.7 \%$ to $81 \%$, according to the Agency for Healthcare Research and Quality (Fuhrmans, 2006). It remains to be seen, if this trend continues, whether Congress will address the health care delivery crisis affecting corporate America.

\section{REFERENCES}

1. $\quad$ Are You Really Covered, Consumer Reports, September 2007, pp. 16-20.

2. Beam, Burton T. Jr., and John J. McFadden (2005) Employee Benefits, $7^{\text {th }}$ Edition: Dearborn Financial Publishing.

3. DeBaise, Colleen, Unhealthy Strategy, Wall Street Journal, 12 March 2007, Sec R-3.

4. $\quad$ Fuhrmans, Vanessa, More Employers Try Limited Health Plans, Wall Street Journal, 17 January 2006, D13.

5. $\quad$ Fuhrmans, Vanessa, Health Savings Plan Start to Falter, Wall Street Journal, 12 June 2007, Sec D1-3.

6. Gurchiek, Kathy, Double-Digit Health Care Cost Increases Forecast, www.shrm.org. Accessed June 14, 2007.

7. Herzlinger, Regina E., Where Are the Innovators in Health Care? Wall Street Journal 19 July 2007, Sec A15 .

8. Kidd Stewart, Janet, Health-Savings Accounts Appealing, but not for all Chicago Tribune 3 December 2006, Sec 5 p. 8. 
9. McQueen, M.P., The Road to Wellness Is Starting at the Office Wall Street Journal 5 December, 2006, Sec D1-3.

10. Rubenstein, Sarah, Is an HSA Right for You? Wall Street Journal 2 February 2006, Sec D1-2.

11. Ryan, Ronda, 2007. Interview with author. San Diego, California, 17 August.

12. Terhune, Chad, Employers Turn to Alternative for Insuring Staff Wall Street Journal 30 July 2007, Sec A15 .

13. Weliver, Jere, 2007. Interview with author. Chicago, Illinois, 12 August.

14. www.optimedhealthplan.com, Accessed August 2, 2006.

15. www.starhrg.com, Accessed August 2, 2006.

\section{NOTES}


NOTES 